\title{
Right ventricular volumes vs. right ventricular ejection fraction are more powerful independent predictors of survival in patients with severe ischemic cardiomyopathy
}

\author{
Noreen Nazir, Rory Hachamovitch, Zoran B Popovic, Scott D Flamm, Thomas Marwick, Deborah Kwon*
}

From 15th Annual SCMR Scientific Sessions

Orlando, FL, USA. 2-5 February 2012

\section{Background}

Right ventricular ejection fraction (RVEF) has been shown to be an independent predictor of mortality after myocardial infarction. However, the predictive value of right ventricluar (RV) assessment in patients with severe ischemic cardiomyopathy (ICM) is unknown.

\section{Purpose}

In patients with severe ICM, we sought to assess the association of RVEF, RV end systolic and diastolic volumes (RV ESVi/RV ESDVi), right ventricular systolic pressure (RVSP) with outcomes in severe ICM.

\section{Methods}

450 patients with $>70 \%$ stenosis in $\geq 1$ epicardial coronary artery $(75 \%$ men, median age 63 years, median LV ejection fraction (EF) $22 \%$, median ESVi 106ml, median RV EF 45\%. Median RVESVi 37.5ml) underwent delayed hyperenhancement-MRI between 2002-2007 (Siemens 1.5-T scanner, Erlangen, Germany) between 2003-2007. CMR evaluation included long and short axis assessment of LV function on balanced steady state free precession images along with assessment of myocardial scar (on phase-sensitive inversion recovery DHE-CMR sequence 10-20 minutes after injection of $0.2 \mathrm{mmol} /$ $\mathrm{kg}$ of Gadolinium dimenglumine). Cox proportional hazards survival modeling, using a primary end-point of all-cause mortality), was used to risk-adjust comparisons. Echocardiograms performed within 60 days were analyzed, and RVSP was assessed as described by American Society of Echocardiogram guidelines.

\section{Results}

Results: Over a follow-up of up to 9 years[mean 5.75 years], 186 deaths occurred. Survival analysis revealed that after adjusting for left ventricular scar burden, left ventricular ESVi, subsequent revascularization, sex, age, mitral valve procedures, $\operatorname{RVSP}(\chi 27.37, \mathrm{p}=0.007)$, RVESVi ( $\chi 2$ 4.81, $\mathrm{p}=0.028$ ), and RVEDVi ( $\chi 2$ 4.11, $\mathrm{p}=$ $0.042)$ were independent predictors of mortality. See Table 1. However, RV EF $(\chi 23.22, p=0.073)$ was not an independent predictor of mortality.

\section{Conclusions}

Conclusions: RV volumes and RVSP, provide independent, incremental prognostic value in patients with severe ICM. RV EF did not provide independent prognostic value.

\section{Funding}

None.

Published: 1 February 2012

Table 1

\begin{tabular}{ccc}
\hline Variable & Chi-square & $\mathrm{p}=$ value \\
\hline RVSP & 7.37 & 0.007 \\
RVESVi & 4.81 & 0.028 \\
RVEDVi & 4.11 & 0.043 \\
RV EF & 3.22 & 0.073 \\
\hline
\end{tabular}


doi:10.1186/1532-429X-14-S1-P3

Cite this article as: Nazir et al:: Right ventricular volumes vs. right ventricular ejection fraction are more powerful independent predictors of survival in patients with severe ischemic cardiomyopathy. Journal of Cardiovascular Magnetic Resonance 2012 14(Suppl 1):P3.

Submit your next manuscript to BioMed Central and take full advantage of:

- Convenient online submission

- Thorough peer review

- No space constraints or color figure charges

- Immediate publication on acceptance

- Inclusion in PubMed, CAS, Scopus and Google Scholar

- Research which is freely available for redistribution

Submit your manuscript at www.biomedcentral.com/submit 